\title{
Pseudo-Kaposi's sarcoma because of suction-socket lower limb prosthesis
}

Pseudo-Kaposi sarcoma is a benign reactive vascular proliferation mainly involving the lower legs, which can be related to acquired chronic venous insufficiency or congenital arteriovenous malformations. In its most common presentation, acroangiodermatitis is seen in patients with chronic venous insufficiency of the lower limbs as an exaggeration of the stasis dermatitis. However, rare reports of acroangiodermatitis include descriptions in amputees (especially in those with poorly fitting suction-type devices), in patients undergoing hemodialysis (with lesions developing distally to arteriovenous shunts) and in patients with paralyzed legs. We report on a 28 year-old-male who presented pseudo-Kaposi's sarcoma in an amputation stump because of suction-socket lower limb prosthesis.

Trindade F, Requena L. Pseudo-Kaposi's sarcoma because of suctionsocket lower limb prosthesis.

J Cutan Pathol 2009; 36: 482-485. (C) 2008 Blackwell Munksgaard.

\section{Felicidade Trindade $^{1}$ and Luis Requena²}

${ }^{1}$ Department of Dermatology, Hospital dos Capuchos, Lisbon, Portugal and

2Department of Dermatology, Fundación

Jiménez Díaz, Universidad Autónoma, Madrid, Spain

\author{
Felicidade Trindade, MD, Department of \\ Dermatology, Hospital dos Capuchos, Alameda \\ Santo António dos Capuchos, 1169-050 Lisbon, \\ Portugal \\ Tel: +351213136300 \\ Fax: +35121356 2208 \\ e-mail: felicidade.trindade@gmail.com
}

Accepted for publication May 1, 2008
Pseudo-Kaposi's sarcoma is a term that encompasses two completely different processes, namely acroangiodermatitis of Mali, which refers to skin lesions on the lower extremities of patients with chronic venous insufficiency, and Stewart-Bluefarb syndrome, which consists of an arteriovenous malformation that clinically resembles Kaposi's sarcoma. ${ }^{1}$

In rare instances, this benign and reactive vascular proliferation may also appear in an amputation stump between 1 and 15 years after amputation in patients with suction-socket lower limb prosthesis, and the diagnosis may be complicated by the resemblance with hemangioma, lymphangioma, Kaposi's sarcoma or lymphangiosarcoma (Stewart-Treves syndrome). ${ }^{2}$

\section{Case report}

A 28-year-old man presented with an erythematous to violaceous plaque on the distal area of the left amputated thigh. He was complaining about pain and edema and progression of the lesion over the past year. He had a history of a road accident with amputation of the left lower limb. Since the past 3 years, he was using suction-socket limb prosthesis.
Physical examination revealed a violaceous plaque on the thigh amputation stump with several small black papules scattered on the surface of the plaque (Figs. 1 and 2). Neither ulceration nor elevation in the skin temperature was observed. The rest of the dermatologic and physical examination was normal.

A cutaneous biopsy of the violaceous plaque was performed, and the histopathologic examination showed a slightly hyperplastic epidermis, with compact hyperkeratosis, focal hypergranulosis and acanthosis as well as a band-like proliferation of dilated capillaries or venules mostly involving the superficial dermis (Fig. 3). These neoformed blood vessels were lined by plump monomorphous endothelial cells and showed thickened rounds walls (Fig. 4). In addition, there were dilated lymphatic vessels, edema of the superficial dermis, fibrillary collagen bundles and numerous horizontally arranged fibroblasts between the dilated blood and lymphatic vessels, all histopathologic features of chronic lymphedema. Interstitially, there were also some extravasated erythrocytes and deposits of hemosiderin. Immunohistochemical studies showed that endothelial cells lining the proliferating capillaries and venules express immunoreactivity for CD31, 


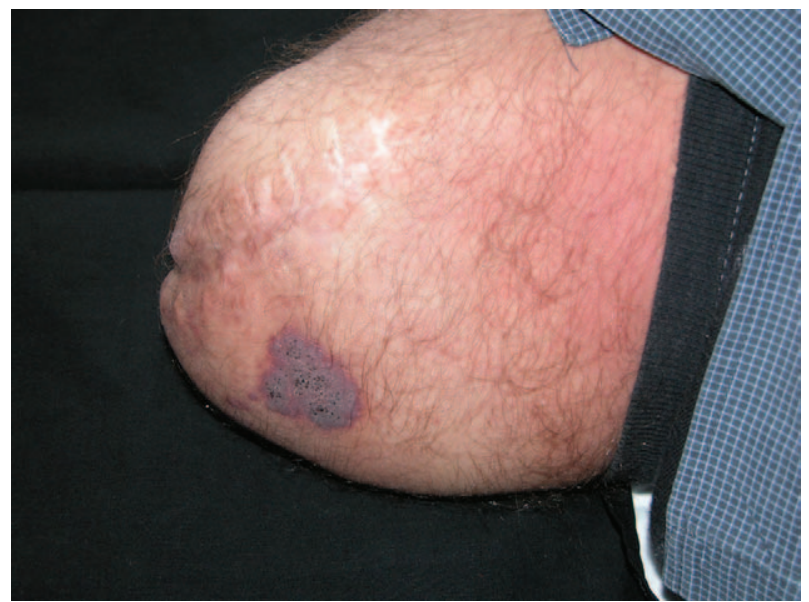

Fig. 1. Clinical appearance of the lesions showing a violaceous plaque dotted with small black papules on the amputation stump.

and genomic material of human herpes virus type 8 (HHV-8) was not detected in the nuclei of the proliferating endothelial cells by immunoperoxidase techniques to show latent protein of HHV-8.

The patient was treated with conservative measures including bed rest and prosthesis avoidance. Complete regression of the lesions was achieved after 4 months, and the use of a different non-suctionsocket limb prosthesis was recommended.

\section{Discussion}

In 1964, Kopf and Gonzalez ${ }^{3}$ first described a condition they termed congenital dysplastic angiopathy. Although it was Earhart who first used the term pseudo-Kaposi's sarcoma in $1974,{ }^{4}$ this clinical picture was first reported by Mali in 1965 as kaposiform cutaneous lesions developed on the extensor surface of the feet in 18 patients with chronic venous insufficiency of the lower limbs. In 1967, Stewart ${ }^{5}$



Fig. 2. Close-up view of the violaceous plaque with the small black papules.

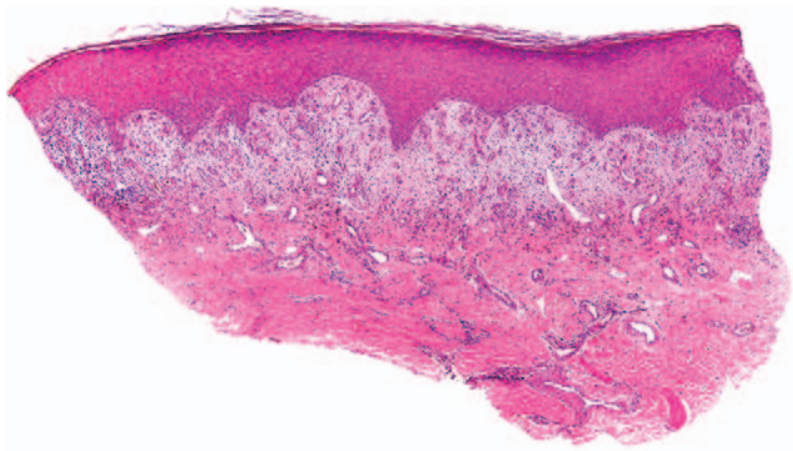

Fig. 3. Histopathologic features of pseudo-Kaposi's sarcoma. A band-like proliferation of thick-walled capillaries and venules lined by plump endothelial cells, dilated lymphatic vessels, fibrillary collagen bundles and fibroblasts horizontally arranged and extravasation of erythrocytes in the papillary dermis (hematoxylineosin stain; original magnification $\times 10$ ).

and Bluefarb and Adams ${ }^{6}$ independently reported the same condition previously described by Mali et al, ${ }^{7}$ but this time, the process was associated with a preexisting congenital arteriovenous malformation.

Nowadays, pseudo-Kaposi's sarcoma is considered as an acquired benign reactive vascular proliferation that may appear in several circumstances including (a) chronic venous insufficiency of the lower extremities (acroangiodermatitis of Mali), ${ }^{7}$ (b) congenital arteriovenous malformations (Stewart-Bluefarb syndrome and Klippel-Trenaunay syndrome), ${ }^{6,8}$ (c) iatrogenic shunts, such as arteriovenous fistula for hemodialysis, and (d) limb anomalies, such as paralyzed extremities, ${ }^{9}$ amputation stumps ${ }^{10}$ and suction-socket lower limb prosthesis. ${ }^{11}$ Although more controversial, there are also reports claiming minor traumas as a cause of pseudo-Kaposi sarcoma. ${ }^{12}$

Acroangiodermatitis of Mali caused by chronic venous insufficiency of the lower extremities is the

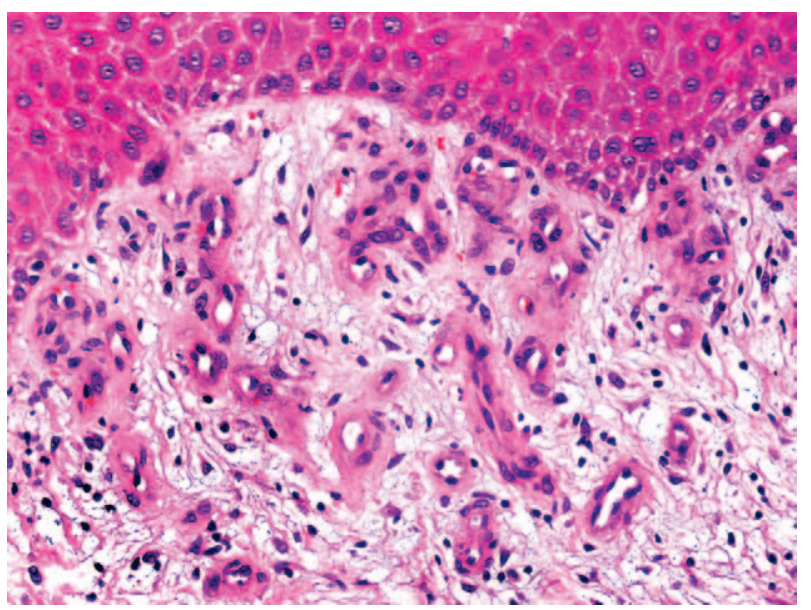

Fig. 4. Higher magnification showing the histopathologic characteristics of the proliferating blood vessels (hematoxylin-eosin stain; original magnification $\times 200$ ). 


\section{Trindade \& Requena}

most common clinical variant of pseudo-Kaposi's sarcoma. The condition is more frequent in males than in females, and most cases have been described in adults. Because it is usually seen as a complication of severe chronic venous stasis, with hypostasis and elevated venous pressure of the lower legs, chronic venous hypertension has been considered as the main pathogenic factor. Severe chronic venous stasis and the insufficiency of the muscle pump can result in an elevated postcapillary pressure. Although the etiology remains still uncertain, other authors proposed that proliferation of fibroblasts and small vessels may be secondary to high perfusion rate in tissues. ${ }^{12}$ Additionally, prostaglandin E1 or a heparin-like factor, which has angiotensin promoting activity, has been suggested as responsible for the lesion development. ${ }^{8}$ A possible role of microtrauma has also been postulated by Pfleger and others. ${ }^{13}$ The lack of the muscle pump and the disturbed innervation of vessels may be of pathogenetic importance in paralyzed extremities. ${ }^{9}$ Other investigators suggested that paralysis could generate the cutaneous lesions increasing venous stasis and enhancing arteriovenous channels. ${ }^{14}$ In our patient, the presence of chronic lymphedema may be also a contributing factor for neoangiogenesis in the lesions of pseudo-Kaposi's sarcoma involving the amputation stump. ${ }^{15}$

Clinically, the lesions begin as violaceous macules and patches that progress slowly into soft, non-tender, red to purple papules and nodules. Patients also present with scaly and indurated purple plaques, and changes of stasis dermatitis are evident on the adjacent skin. Bilateral lesions are usually associated with chronic venous insufficiency, whereas unilateral lesions suggest an underlying vascular malformation or an arteriovenous shunt.

Lesions identical to those of acroangiodermatitis of Mali may be seen in the distal part of an amputation stump, and reports of acroangiodermatitis have appeared in the literature more frequently because the increased use of the suction-socket prosthesis that uses suction as a mechanism for securing the socket to the stump by using a valve system to create negative pressure in the stump-socket environment. In these cases, pseudo-Kaposi's sarcoma is probably caused by the negative pressure in the stump-socket environment, leading to altered local circulation and the proliferation of small vessels. ${ }^{16}$ Repeated microtrauma to the skin of the stump may occur if the fit of socket and stump is not perfect, leading to proliferation of fibroblasts and small vessels and in particularly sensitive tissue such as the skin on an amputation stump. ${ }^{17}$ Acroangiodermatitis occurring on amputation stumps because of socket prostheses is clinically reported as a stump edema with violaceous macules, patches and nodules.,2,16,17 There is one report of amputation stump dermatitis, cli- nically resembling verrucous hyperplasia, but with predominant histologic aspects of acroangiodermatitis in a patient with a suction-socket lower limb prosthesis. $^{11}$

Histopathologic findings of early lesions are those of an exaggerated stasis dermatitis, including increased number of thick-walled capillaries and venules lined by plump endothelial cells, extravasation of erythrocytes and deposits of hemosiderin. ${ }^{1}$ In long-standing lesions of pseudo-Kaposi's sarcoma, the full thickness of the papillary dermis is involved, showing proliferation of round, dilated, thick-walled capillaries, with plump endothelial cells, often arranged in a lobular pattern. ${ }^{18}$ Neovascularization is accompanied by fibrosis with spindle cells, extravasation of red blood cells and deposition of hemosiderin. Venules and deeper vertical small veins can also become tortuous and hypertrophic. A few interspersed inflammatory cells and eosinophils may be noted. In contrast with patch stage lesions of Kaposi's sarcoma, proliferation of irregular jagged vascular channels, with slit-like lumina, surrounding preexisting capillaries is not seen in lesions of pseudoKaposi's sarcoma. Furthermore, authentic Kaposi's sarcoma usually spares the papillary dermis in its early stages of evolution.

Immunohistochemically, plump endothelial cells of the proliferating capillaries and venules express immunoreactivity for blood endothelial cell markers, such as CD31 and factor VIII-associated antigen, whereas the proliferative fibroblast-like spindle cells in the surrounding stroma are positive for factor XIIIa. ${ }^{19}$

New techniques developed to avoid misdiagnoses include immunohistochemical studies with CD34 antigen (the human progenitor cell antigen) expression to distinguish lesions of pseudo-Kaposi's sarcoma from those of authentic Kaposi's sarcoma. CD34 positivity is detected in both endothelial cells and perivascular spindle cells of Kaposi's sarcoma, whereas there is a complete absence of CD34 expression in perivascular cells of pseudo-Kaposi's sarcoma. ${ }^{20}$ But more recently, the immunohistochemical demonstration of genomic material of HHV-8 in the nuclei of the proliferating cells in lesional skin has become the gold standard technique for histopathologic differential diagnosis between authentic Kaposi's sarcoma and all other vascular proliferations that may simulate Kaposi's sarcoma and that may be included under the generic name of Kaposi's sarcoma simulators. HHV-8 may be immunohistochemically shown in the nuclei of the proliferating cells of lesions of Kaposi's sarcoma, both in all stages of evolution and in all epidemiologic variants (classic type, African type, human immunodeficiency virus associated and immunosuppressive drug associated) of the process. In contrast, immunohistochemical studies in proliferating endothelial cells of all vascular proliferations that 
may be considered as histopathologic simulators of Kaposi's sarcoma have resulted negative for HHV-8. ${ }^{21}$

Complications of pseudo-Kaposi's sarcoma include ulcers, infection, hemorrhage, pain, limb hypertrophy, bone demineralization and congestive heart failure. A new complication was described recently consisting of pincer nail deformity secondary to artificial arteriovenous hemodialysis fistula, which correlated with a restoration of the normal features of the limb after ligation of the fistula. ${ }^{22}$

Treatment tends to be conservative. Most of the treatment reports are of anecdotal nature. Compression therapy has been shown to heal ulcers secondary to pseudo-Kaposi's sarcoma and leads to regression of the lesion. ${ }^{23}$ Erythromycin was found to be effective. ${ }^{7}$ Therapeutical options consist of corrective arteriovenous shunts through embolization or surgery, surgical ligation of vessels or elastic compression therapy in chronic venous insufficiency. Anticoagulant therapy is useful in patients with thrombophilic alterations. ${ }^{1}$ Individual lesions may persist unchanged for several years.

Our patient was successfully treated by conservative measures, with rest and avoidance of the prosthesis, and later, we recommended the use of a different non-suction-socket limb prosthesis.

\section{References}

1. Requena L, Sangueza OP. Cutaneous vascular proliferations. Part II. Hyperplasias and benign neoplasms. J Am Acad Dermatol 1997; 37: 887.

2. Virgili A, Trincone S, Zampino MR, Corazza M. Acroangiodermatitis of amputation stump. Eur J Dermatol 2003; 13: 402.

3. Kopf AW, Gonzalez V. Congenital dysplastic angiopathy of the skin and underlying tissues. Arch Dermatol 1964; 90: 360.

4. Earhart RN, Aeling JA, Nuss DD, et al. Pseudo-Kaposi sarcoma. A patient with arteriovenous malformation and skin lesions simulating Kaposi sarcoma. Arch Dermatol 1974; 110: 907.

5. Stewart WM. Fausse angiosarcomatose de Kaposi par fistules arterioveneuses multiples. Bull Soc Fr Derm Syph 1967; 74: 664

6. Bluefarb SM, Adams LA. Arteriovenous malformation with angiodermatitis. Stasis dermatitis simulating Kaposi's disease. Arch Dermatol 1967; 96: 176.

7. Mali JWH, Kuiper JT, Hamers AA. Acro-angiodermatitis of the foot. Arch Dermatol 1965; 92: 515.
8. Samad A, Dodds S. Acroangiodermatitis: review of the literature and report of a case associated with symmetrical foot ulcers. Eur J Vasc Endovasc Surg 2002; 24: 558.

9. Landthaler M, Langehenke H, Holzmann H, et al. Akroangiodermatitis Mali (Pseudo-Kaposi) an gelähmten Beinen. Hautarzt 1988; 39: 304.

10. Hödl S, Kresbach H. Kaposiforme Angiodermatitis (PseudoM. Kaposi) am Amputationsstumpf. Eine neue Entitat. Hautarzt 1988; 39: 302.

11. Sbano P, Miracco C, Risulo M, Famiani M. Acroangiodermatitis (pseudo-Kaposi sarcoma) associated with verrucous hyperplasia induced by suction-socket lower limb prosthesis. J Cutan Pathol 2005; 32: 429.

12. Del-Rio E, Aguilar A, Ambrojo P, Velez A, Sanchez Yus E. Pseudo-Kaposi sarcoma induced by minor trauma in a patient with Klippel-Trenaunay-Weber syndrome. Clin Exp Dermatol 1993; 18: 151.

13. Pfleger L. Zur pathogenes unklarer purpuraformen. Arch f Dermatologie u Syphilis 1954; 197: 187.

14. Meynadier J, Malbos S, Guilhou JJ, Barneon G. Acroangiodermatitis developing on paralytic limbs. Dermatologica 1980; 160: 190.

15. Meulenbelt HE, Geertzen JH, Dijkstra PU, Jonkman MF. Skin problems in lower limb amputees: an overview by case reports. J Eur Acad Dermatol Venereol 2007; 21: 147.

16. Badell A, Marcoval J, Graells J, et al. Kaposi-like acroangiodermatitis induced by a suction-socket prosthesis. $\mathrm{Br} \mathrm{J}$ Dermatol 1994; 131: 915.

17. Kolde G, Worheide J, Baumgartner R, Bröcker EB. Kaposi-like acroangiodermatitis in an above-knee amputation stump. Br J Dermatol 1989; 120: 575.

18. Requena L, Sangueza OP. Cutaneous vascular proliferations. Part III. Malignant neoplasms, other cutaneous neoplasms with significant vascular component, and disorders erroneously considered as vascular neoplasms. J Am Acad Dermatol 1998; 38: 143.

19. Murakami Y, Nagore S, Hori Y. Factor XIIIa expression in pseudo-Kaposi sarcoma. J Dermatol 1991; 18: 661.

20. Kanitakis J, Narvaez D, Claudy A. Expression of the CD34 antigen distinguishes Kaposi's sarcoma from pseudo-Kaposi's sarcoma (acroangiodermatitis). Br J Dermatol 1996; 134: 44.

21. Robin YM, Guillou L, Michels JJ, Coindre JM. Human herpesvirus 8 immunostaining. A sensitive and specific method for diagnosing Kaposi sarcoma in paraffin-embedded sections. Am J Clin Pathol 2004; 121: 330.

22. Hwang SM, Lee SH, Ahn SK. Pincer nail deformity and pseudo-Kaposi's sarcoma: complications of an artificial arteriovenous fistula for haemodialysis. Br J Dermatol 1999; 141: 1129.

23. Pires A, Depairon M, Ricci C, et al. Effect of compression therapy on a pseudo-Kaposi sarcoma. Dermatology 1999; 198: 439 . 